\title{
Research of Prevention and Control of the Construction Project Contract Law
}

\author{
Zhan $\mathrm{Li}^{1, \mathrm{a}}$ \\ ${ }^{1}$ Sichuan College of Architectural Technology, Sichuan,Deyang 618000,China \\ a397451499@qq.com
}

Key words: construction contract, legal risk, prevention and control

\begin{abstract}
The construction project is widely existed in many areas of the social life, which has the characteristics of complicated distribution project, long construction time and wide scope, so it results the project containing many risks in the process of construction. Compared with other contract, the construction project contract has the features of diversified main contract, miscellaneous terms of the contract and longer fulfillment cycle. Therefore, in order to conclude the complete content contract and precise construction contract, theoretical knowledge and practical experience of legal professional and related construction industry are needed. In this paper, research on the prevention and control of legal risk to the construction contract based on the theory of law was carried with the related theories of other disciplines of management and economics.
\end{abstract}

\section{Introduction}

With the sustained and rapid development of China's economy, increased investment in all sectors of society, 2008 annual investment in fixed assets 172291 billion yuan according to the annual statistical bulletin issued by the National Bureau of statistics show, which has growth $25.5 \%$ than going up year. In the view of urban and rural, urban investment is 148167 billion yuan with increase of $26.1 \%$; rural investment is 24124 billion yuan with increase of $21.5 \%$. In the view of regional perspective, the eastern region investment is 87412 billion yuan with increase of $20.9 \%$; the central region investment is 45384 billion yuan with increase of $32.6 \%$, the western region investment is 35839 billion yuan with increase of $26.9 \%$. Among them, China's rapid economic development in the project areas is mainly that the expanded project investment scale, increased technical level especially high-tech investment ratio and production fund[1]. Therefore, the construction industry has become the pillar industry of our national economy. Prevention and control of the construction project contract legal risk belongs to the management component of construction project contract[2]. Because of the prevention of the legal risks of construction contracts abroad for practice, and most of them are qualitative discussion, and the theory research and the practice exploration of domestic is just in the initial stage, and the basis is very weak. In this paper, further enrich and deepen the theoretical research for the prevention and control of the construction project contract risk, was researched in order to improve the construction contract risk, and to recognize the important role of risk prevention and control in construction contract management, to improve contract subject consciousness for risk prevention and control.

\section{An outline of the legal risk of the construction engineering contract}

\section{A.Legal risk and legal risk of contract}

Legal risk is a kind of very strong practice risk; the concept is more in line with the areas to be defined. Therefore, through the study of different scholars for the legal definition of risk, it can be found that most of the scholars defined extend legal risk according to the theory of the study. Although the definitions for legal risks are different, but the essence is around three words, namely: legal behavior, loss and possibility. Legal risks of the contract are all the risks caused by contract in the legal risk of contract[3]. The contract risk generalized besides the risk we 
have on the matter, also includes the debt risk, namely all kinds of risks during the process of the contract [4].

B.The connotation and characteristics of the construction project contract and its legal risk

A contract for construction project is the contractor of construction project contract, in which the employer pays the price of the contract. The object of construction contract is the project. This project is referred to civil engineering and construction industry within the lines, pipelines, equipment installation engineering construction, expansion, reconstruction and large construction decoration activities, mainly including housing, roads, pipelines, ports, bridges, airports, mine, power plant, reservoir [5]. Subject construction is the employer and the contractor. The employer is the general construction project construction unit, namely the investment unit in the construction of the project .The basic obligations of the contractor is in accordance with the contract of construction tasks, including survey, design and construction. The basic obligation of the employer is timely and full payment of the project. Therefore, the contract law of our country stipulates the construction contract including the contract of construction engineering survey, design contract for construction project and the construction contract.

The legal risk of the construction contract belongs to legal risk category of the contract, which is beyond doubt, but the legal risk of this kind of contract, in addition to features of legal risk of the general contract, the legal risk prevention and control of construction project contract has its own particularity, mainly manifested in the following aspects:

C.The long-term construction contract legal risk prevention and control.

Construction of the project is a continuing, gradual process type, the biggest characteristics of construction project long operation cycle, and the performance is a long-term process of contract. The time from the planned investment, review project, bidding, bidding, contract, perform to engineering task completion is from a few years to decades ranging. Therefore, legal risk prevention and control of construction project contract are persistent and permanent.

$D$. The logic of the legal risk prevention and control of construction project contract.

The construction project process is a logical process, such as construction projects must first survey design and then construction. Therefore, the prevention and control of legal risk of the construction contract must be logical. And the construction of legal risk in project contract's influence is not only limited to a particular site, but has spread development traits by the correlation between risk. For example, and the design contract performance directly determines the performance and the performance of the quality of construction contract. Therefore, risk management must be engaged in risk prevention and control work from the comprehensive and related compound angle.

E.Dynamic legal risk prevention and control of construction project contract.

The contract risk general course is a dynamic process, but the difference lies in the progress of the project construction with a contract to perform, the different contract's risk prevention key nature is different. Therefore, the prevention and control of construction engineering and legal risk is with the inheritance the relationship between contract performance dynamic processes to continuously adjust.

F.Comprehensive legal risk prevention and control method of construction project contract.

Construction project contract is different in the contents of many kinds of large, complex process of the terms of the contract; there are differences in contract or the performance of the way, especially in engineering construction survey, design or construction, in which the digital standard of construction engineering is needed. Legal risk of contract in both theory and practice are involved in practical discipline theory, which results a comprehensive prevention and control method.

G.The complexity of legal risk prevention and control of the construction project contract.

The complexity of legal risk prevention and control of construction project contract are closely linked its features, mainly in the number of construction contract, so the contract 
subject relationship is complex, and the construction project contract is affected not only by the "contract law", "construction law", "Bidding Law" and other legal department's adjustment. Because of the main contract qualification requirements, the establishment and implementation process of contract are more complex.

H.The interests of legal risk prevention and control of construction project contract.

The construction itself is a kind of business investment. From the point of view of economics, the risk prevention and control belong to commercial cost areas. Therefore, in a certain range, investment in construction of legal risk prevention and control of the construction project has a direct proportion the profit output of contract. Therefore, the prevention and control of legal risk of the construction contract has a certain economic interests.

I. Risk of construction project contract legal risk prevention and control.

The legal risk of the construction contract to prevention and control is taken to avoid or reduce losses through the implementation of specific prevention and control strategies. But due to various limitations of the identification and analysis of technical risk, the legal risk of the construction contract can not be completely avoided; the formulation of risk prevention and control measures and the implementation itself have the risk.

\section{Causes analysis and prevention and control program of legal risk in construction project contract}

\section{A.Causes of legal risk of construction project contract}

Causes of legal risk of construction project contract can be analyzed from the macro and micro aspects. The macro causes of legal risk of the construction contract are mainly induced by the legal environment of defects. On microscopic, all kinds of legal risk factors are considered in Signing and implementing process of construction project contract. The macro causes of legal risk of contract for construction project mainly includes legislative, administrative, judicial and law-abiding factors.

The microcosmic factors of legal risk of the construction contract can be divided into the main contract, the contract object, form of contract, performance and other factors. When a dispute was occurred in the contract, the parties seek resolved relief means through legal means. But at present, there are many problems in China's judicial system; especially the judicature is not independent in the trial work of the judges, who can not only take the fact as the basis, and take the trial of case law as the criterion. Therefore, judicial independence is one of the legal risks of the construction project contract in China.

\section{B.Legal risk prevention and control program of construction project contract}

The construction project contract legal risk prevention and control program in general can be divided into three steps: the first step is the construction project contract legal risk identification and analysis; the second step is the construction to perform the contract for construction project specific legal risk prevention and control system; the last is the implementation of specific prevention and control strategies. As shown in figure 1:

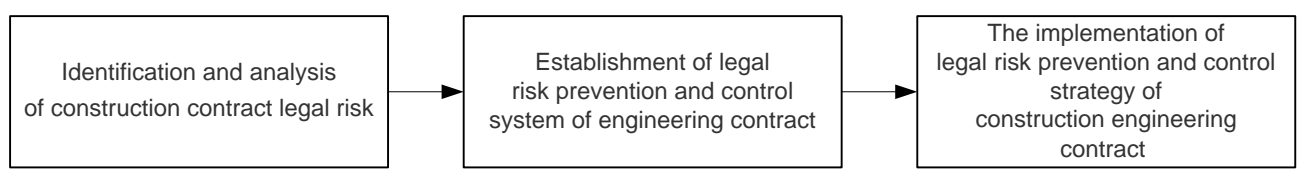

Figure 1 The legal risk prevention and control process of construction project contract

\section{Specific measures to improve the construction project contract legal risk prevention and control system}

Legal risk prevention and control of construction project contract needs a good legal environment in macro. Constructing a good legal environment can be improved from the perfect 
relevant legislation, perfect law enforcement mechanism, perfect judicial system, the judicial independence, the improved law awareness. The micro control system of legal risk of construction project contract includes the legal risk prevention and control measures should be taken in contract parties, legal risk prevention and control measures taken by the employer and the contractor.

First of all, the comprehensive review and analysis of the contract process has an indispensable status in preventing and controlling the legal risks of the construction contract. Before signing the contract, the parties of the contract are to be carefully, comprehensively reviewing contracts and risk analysis, the advantages and disadvantages of each clause in the contract should be clear understanding. When signing the contract, professional personnel familiar with the project and project contract shall be appointed to do the related matters. In the contract negotiations, the parties should make serious discussion of the contract terms and the risk, at the end of the negotiations and contract before signing the contract, the parties must also make a comprehensive analysis and review of the contract, such as found for contract review questions have been put into effect, risk adverse harsh terms have been revised. Again, after the amendment or supplement contract provisions may bring new problems and risks, and the original contract terms are conflicting or inconsistent, may still exist loopholes and uncertainty of law, and there is still a risk countermeasures. Moreover, any modification of tender and contract conditions, signing any new supplementary agreement, supplementary agreement, must be approved by the contract review and record.

\section{References}

[1] Chen Chaowen. Discussions on the Reform of Tanching Practice for Computer Science Majors[J]. Journal of Nanning Teachers College, 2005, 22(3):75-77.

[2] DENG Jing-sheng. The new view about reform of the method of pre-service teacher education practice under the background of new curriculum[J]. CAREER HORIZON, 2012, 8(9): 81-83.

[3] Hulman LS.. Knowledge and Teaching: Foundations of the New Reform[J]. Harvard Educational Review, 1987, 57 (1): 135-143.

[4] LIU Xu-dong. On Educational Practice Ability of Normal Students and the Reform of Education and Internship Program[J]. Contemporary Education and Culture, 2011, 3(2): 74-79.

[5] Dominic Helps, Peter Sheridan. "Construction Act Review" . Construction Law Journal. 2007 